\title{
INVESTIGATING INHIBITING FACTORS AFFECTING MOOCS ADOPTION AMONG TEACHERS IN HIGHER EDUCATION INSTITUTIONS OF INDIA
}

\author{
Priyanka Bhaskar \\ Doon Business School, Dehradun, Uttarakhand, India \\ bhaskar.priyanka06@gmail.com \\ Amit Joshi \\ ICFAI Business School, ICFAI University, Dehradun, Uttarakhand, India \\ insojtima@gmail.com \\ Padmalosani Dayalan \\ University of Technology and Applied Sciences, Ibra, Oman \\ d.padmalosani@gmail.com
}

\begin{abstract}
Massive Open Online Courses (MOOCs) has the potential to eradicate the digital divide and endorse education globally among the learners in the education industry. Through MOOCs platforms, teachers can upgrade their knowledge skills and abilities in their respective fields. The present study aims to identify the inhibiting factors underlying the adoption of MOOCs by teachers employed in higher education institutions. The research has employed an Interpretative Phenomenological Analysis of qualitative research methodology. In this research, teachers from the identified Universities of Uttarakhand, India are selected as the respondent to investigate the factors affecting the adoption of MOOCs. Findings reveal that technological barriers, financial barriers, and lack of awareness act as inhibiting factors in adopting MOOCs by teachers of HEl. This study also contributes to the literature by assessing the factors influencing teachers' intention to adopt Massive Open Online Courses for learning. Through this paper, the three stakeholders of MOOCs, that is teachers, $\mathrm{HEl}$ and MOOC provider are suggested measures that will enhance the support and acceptability of the online courses.
\end{abstract}

Keywords: Massive Open Online Courses (MOOCs), Teachers, Universities, Technology adoption.

DOI: https://doi.org/10.24818/beman/2021.11.2-06

\section{INTRODUCTION}

Massive Open Online Course (MOOCs) is an emerging source of e-learning for anyone from anywhere. MOOCs are offered by renowned universities and educational institutions across the globe through 
Iversity, edX, Coursera, National Programme on Technology Enhanced Learning (NPTEL), Udacity, IITBX Udacity, mooKIT, Zoom, Study Web for Active Young Expiring Minds (SWAYAM), Future Learn, Open2Study, etc. Individuals around the world have enrolled in Massive Open Online Courses. These platforms are mainly used by academicians, instructors, students, professionals, and web learners to realize their educational and learning process for up-skilling their knowledge repository (Bhaskar et al., 2020; Gupta et al., 2015). MOOCs have predominantly benefitted citizens of developing with lower socioeconomic status and less education facilities. Considering the advantages derived from MOOCs by learners in other countries, like China (Hew et al., 2020), Pakistan (Raza et al., 2020); Greece (Koutsodimou and Jimoyiannis, 2015) and Jordan (Abu-Shanab and Musleh, 2018), it is substantiated that studies related to the Indian context are deficient. MOOCs provide opportunities to learn from the world's leading universities. Due to easy accessibility through the internet (Sanchez-Gordon and Luján-Mora, 2014), variety of choices for learners (Means et al., 2009), cost-efficient for learners (Mohapatra and Mohanty, 2016), quality learning materials (Barclay \& Logan, 2013) MOOCs have been a popular way of learning.

Teachers need to keep up with the rapid pace of dynamism in the educational field. The continuous need for innovations and extensive use of technologies in higher education institutes make continuous learning imperative for teachers. MOOCs provide flexibility of learning to teachers. They are able to acquire additional knowledge from their busy work schedules and are exposed to course content and resources. Even though, teachers don't have institutional, financial, or societal support they are required to maintain their credentials and continuously develop their proficiency and skills. MOOCs offer both tangible and intangible benefits which facilitate the teachers to accomplish career and educational goals. MOOCs is worthwhile in according to better career prospects, achieving academic goals, salary increase, promotion, credit in academic degrees, and also support in commencing a new business (Zheng et al., 2015). MOOCs is widely used by students to obtain knowledge and additional certification, but online courses are not very famous among teachers. Though MOOCs offer multiple benefits to teachers like professional development Bakogianni et al., (2020); Sharma (2020); Misra, (2018); Kleiman et al., (2014); Ambadkar, (2014); career growth (Zheng et al., 2015), but still the number of enrolled teachers for learning form MOOCs is extremely low. A small number of researchers have focussed on teacher's perspectives and their adoption of MOOCs (Raza et al., 2020; Nagasampige et al., 2018; Koutsodimou and Jimoyiannis, 2015). The present study intends to identify the inhibiting factors underlying the adoption of MOOCs by teachers in the higher education institutions of India. Teachers are selected from the Universities of Uttarakhand, India. Education is the pivot of development and growth, the paper will rest a positive 
implication on all the major stakeholders of higher education that is: teachers, institutions, and MOOC providers.

\section{LITERATURE REVIEW}

MOOCs provide opportunities to learn from the world's leading universities through online platforms. MOOCs is popular for several reasons such as easy accessibility through the internet (Sanchez-Gordon and Luján-Mora, 2014), variety of choices for learners (Means et al., 2009), cost-efficient for learners (Mohapatra and Mohanty, 2016) and quality learning materials (Barclay \& Logan, 2013). Prior research have studied learner's perspective on MOOCs by using the technology-user-environment perspective, innovation resistance, task-technology fit; social cognitive theory; the unified theory of acceptance and use of technology (Tseng, et al., 2019); theory of planned behaviour, social support theory; regulatory focus theory; self-determination theory, network externalities; technology acceptance Model; SDT and theory of relationship quality and the expectation confirmation paradigm. However, majorities of these models have been applied to understand the student's intentions to adopt MOOCs. Gupta (2019) and few researchers have focussed on teacher's perspectives and their adoption (Raza et al., 2020; Nagasampige et al., 2018; Koutsodimou, and Jimoyiannis, 2015). Table 1 shows the studies conducted on a different type of learner's intention to adopts MOOCs

\section{TABLE 1: STUDIES ON THE DIFFERENT TYPE OF LEARNER'S INTENTION TO ADOPTS MOOCS}

\begin{tabular}{|l|l|}
\hline Learner Categories & References \\
\hline Students & $\begin{array}{l}\text { Gupta (2021); Raza et al., (2020); Gupta and Maurya (2020); (Hakami et } \\
\text { al., 2017); Hew et al., (2020); Gupta (2020); Gupta, (2019); Chopra et al., } \\
\text { (2019) Nagasampige et al., (2018); Wang and Baker, (2015); Zheng et } \\
\text { al., (2015); Saadatmand and Kumpulainen, (2014); Hew and Cheung, } \\
\text { (2014); Abeer and Miri, (2014); Zutshi, et al., (2013) }\end{array}$ \\
\hline Teachers & $\begin{array}{l}\text { Raza et al., (2020); Nagasampige et al., (2018); Koutsodimou, and } \\
\text { Jimoyiannis, (2015) }\end{array}$ \\
\hline
\end{tabular}

\section{RESEARCH METHODOLOGY}

Interpretative phenomenological analysis (IPA) of qualitative research methodology is employed in this research. IPA aims to explore and understand in detail about the person's experience of a particular phenomenon. Smith (1996) precisely stated that IPA is deployed in situations where the sample size understudy is small, and they are required to be analyzed at greater lengths. Many authors have used IPA 
Bhaskar, P., Joshi, A. \& Dayalan P.

INVESTIGATING INHIBITING FACTORS AFFECTING MOOCS ADOPTION AMONG TEACHERS IN HIGHER

EDUCATION INSTITUTIONS OF INDIA

in recent research studies (Gupta and Bhaskar, 2020; Joshi et al., 2020) This study has done an in-depth analysis by using semi-structured interviews with teachers of the private Universities situated in Uttarakhand, India. Few of the questions that are asked include

- Have you heard about MOOCs? What do you know about it?

- Have you acquired any certificate from MOOCs? Why or why not?

- What reasons will you enumerate for not acquiring a certificate from MOOCs?

- Do you have any institutional policy to do MOOCs?

- Are you interested to pursue MOOCs? Why or why not?

In this research, teachers have been selected as the respondent to understand the inhibiting factors in adopting MOOCs. In totality, the sample profile includes 11 teachers who participated in this study, as per Smith and Osborn, (2003) the IPA study sample size can range from 1 to 15. The sample of the study comprises of 6 males and 5 females belonging to the age group 23 to 55 years with a minimum of 3 years of teaching experience. 7 participants were post-graduates and 4 were having a PhD degree. The average time duration of the interview was 50 minutes and the overall timing of the interviews fluctuated between 30 to 115 minutes.

\section{RESULTS}

The findings have been grouped under two larger units known as "meaning units" or "themes," Themes revealed that the inhibiting factors to adopt MOOCs among the teachers of Higher education institutions are technological barriers, financial barriers, and lack of awareness.

\section{Theme-1: Lack of awareness}

Lack of awareness is one of the prominent factors that is identified as a barrier by most of teachers. They were not familiar with the MOOCs and the various platforms that offer online courses. Teachers also faced difficulty in understanding the functionality of MOOCs platforms which resulted in a negative attitude towards MOOCs.

"I have heard about MOOCs, but not sure how it functions like enrolling process, online fees payment, mode of examination, etc. " (Respondent-1)

"I want to enrol in MOOCs, but I face difficulty in selecting the platform for learning courses. Same course is offered by Course Era, EdX, NPTEL, etc. I can't find any differences among them" (Respondent-5) 


\section{Theme- 2: Technological barriers}

Teachers were not well versed in the online learning process. They face many technical difficulties related to hardware, software, uninterrupted power supply, and internet connectivity which demotivates them to enrol for MOOCs. Many teachers do not have an upgraded laptop or software to run the online courses. Many online courses require good internet connectivity to play pre-recorded videos and completing the live online assessment.

"I wish to do online courses, but I do not have a good internet network connection at home. It keeps on getting disconnected due to uninterrupted power supply" (Respondent-3)

\section{Theme- 3: Time constraints}

Teachers were not inclined towards MOOCs due to time constraints as they have to devote additional timeslot from their daily routine. They feel burdened with existing job duties and responsibilities; it becomes difficult for them to give extra time to learn from MOOCs. Some courses even need to be finished within the stipulated time, it becomes difficult to adhere to the timeline while managing their personal and professional life.

"I wish to do online courses, but I don't have time to devote on a daily basis. I have so many tasks already lying on my desk, which need to be completed at the earliest to meet the deadlines of my universities" (Respondent-3)

\section{DISCUSSION AND CONCLUSION}

Teachers are not aware of online platforms, types of programs, and different courses that are offered under MOOCs. Even though the conventional courses and institutions offering the courses are well recognized, still MOOCs is not well recognized, and teachers are not aware of their existence and benefits. The only medium through which teachers are aware of MOOCs is through the internet, that too when they show a little interest and take initiative. The awareness about MOOCs and its benefit is restricted to experienced teachers who are involved in research and development. (Nagasampige, et al., 2018; Castano-Munoz et al., 2018; Malita et al., 2018). MOOCs need consistent technological infrastructure and high-speed internet connection without which it becomes difficult for the teachers to complete the course. In developing countries, internet connectivity is a major problem that demotivates teachers to adopt online courses (Vinay \& Bhaskar, 2020; Joshi et al., 2020; Kizilcec \& Halawa, 2015; Bhaskar et al., 2020). Teachers felt encumbered due to existing job commitments, consecrate time to complete courses MOOCs will disturb their work-life balance. MOOCs require teachers must devote significant amounts of time and money (Tseng et al., 2019; Chaudhary and Bhaskar, 2016). Teachers need to keep up with the rapid pace 
of change in the educational innovations and technologies for learning; MOOCs give flexibility and convenience to teachers to learn additional from their busy work schedules with the added advantage of the availability of free content and resources. Teachers are responsible for continually renewing and developing their knowledge and skills.

MOOCs have emerged as a significant COMPONENT for teachers over the years. It is imperative to understand which factors influence the teachers to enrol in MOOCs. The study holds relevance to various stakeholders. Higher education institutions will be able to recognize inhibitors and can take corrective measures for promoting MOOCs among teachers. Secondly, MOOCs providers will be able to focus on developing self-paced courses in cutting edge areas at affordable prices to motivate teachers for enrolling in MOOCs for personal and professional development. Thirdly, teachers will be able to identify the utility and device measures to overcome those inhibiting factors and can focus on the motivators for enrolling in MOOCs for career growth and development. The higher education institute may provide financial and technical support to the teachers to enhance their skills through MOOCs. Providing time and including MOOCs certification as one of the parameters of appraisals will motivate the teachers to adopt MOOCs.

\section{LIMITATIONS}

The current study is not aloof with limitations. The future study can create a strategy and confirm the conclusion with the triangulation method. The study is based in India, the results may vary if conducted in other parts of the world. The study can be conducted with a different set of participants to have detailed awareness about the inhibitors of MOOCs for teachers of HEl.

\section{REFERENCES}

Abeer, W., \& Miri, B. (2014). Students' preferences and views about learning in a MOOC. ProcediaSocial and Behavioral Sciences, 152, 318-323.

Abu-Shanab, E. A., \& Musleh, S. (2018). The adoption of massive open online courses: Challenges and benefits. International Journal of Web-Based Learning and Teaching Technologies (IJWLTT), 13(4), $62-76$.

Ambadkar, R. (2014). MOOCs: An aid for professional development of teachers in India. Global Online Electronic International Interdisciplinary Research Journal, 3(1), 91-96.

Bakogianni, E., Tsitouridou, M., \& Kyridis, A. (2020). MOOCs in teachers' professional development: examining teacher readiness. Academia, (18), 9-40.

Barclay, C., \& Logan, D. (2013, December). Towards an understanding of the implementation \& adoption of massive online open courses (MOOCs) in a developing economy context. In Proceedings Annual Workshop of the AIS Special Interest Group for ICT in Global Development (Vol. 6, pp. 1-14). 
Bhaskar, P. Joshi, A., \& Chopra, G., (2020). Career Growth and Development: The Buzzword Is Continuing Education. International Journal of Knowledge and Learning. Volume 14, (1) , 39-62

Bhaskar, P., Tiwari, C. K., \& Joshi, A. (2020). Blockchain in education management: present and future applications. Interactive Technology and Smart Education.

Castaño-Muñoz, J., Kalz, M., Kreijns, K., \& Punie, Y. (2018). Who is taking MOOCs for teachers' professional development on the use of ICT? A cross-sectional study from Spain. Technology, Pedagogy and Education, 27(5), 607-624.

Chaudhary, N. S., \& Bhaskar, P. (2016). Training and Development and Job Satisfaction in Education Sector. Training and Development, 16.

Chopra, G., Madan, P., Jaisingh, P., \& Bhaskar, P. (2019). Effectiveness of e-learning portal from students' perspective. Interactive Technology and Smart Education.

Gupta, K. (2019). An application of AHP for students' perspectives on adopting MOOCs. Management Science Letters, 9(13), 2337-2336.

Gupta, K. P. (2019). Investigating the adoption of MOOCs in a developing country: Application of technology-user-environment framework and self-determination theory. Interactive Technology and Smart Education.

Gupta, K. P. (2021). Understanding learners' completion intention of massive open online courses (MOOCs): role of personality traits and personal innovativeness. International Journal of Educational Management.

Gupta, K. P., \& Bhaskar, P. (2020). Inhibiting and Motivating Factors Influencing Teachers' Adoption of AlBased Teaching and Learning Solutions: Prioritization Using Analytic Hierarchy Process. Journal of Information Technology Education: Research, 19, 693-723.

Gupta, K. P., \& Maurya, H. (2020). Adoption, completion and continuance of MOOCs: a longitudinal study of students' behavioural intentions. Behaviour \& Information Technology, 1-18.

Gupta,K.P, Singh, S., \& Bhaskar, P. (2015). Employees' perspectives on continuing management education (CME): a study of BPO industry in Noida. Researchers World, 6(2), 141.

Hakami, N., White, S., \& Chakaveh, S. (2017). Motivational factors that influence the use of MOOCs: Learners' perspectives. In Proceedings of the 9th International Conference on Computer Supported Education (CSEDU 2017) (pp. 323-331).

Hew, K. F., \& Cheung, W. S. (2014). Students' and instructors' use of massive open online courses (MOOCs): Motivations and challenges. Educational research review, 12, 45-58.

Hew, K. F., Hu, X., Qiao, C., \& Tang, Y. (2020). What predicts student satisfaction with MOOCs: A gradient boosting trees supervised machine learning and sentiment analysis approach. Computers \& Education, 145, 103724.

Joshi, A., Vinay, M., \& Bhaskar, P. (2020). Impact of coronavirus pandemic on the Indian education sector: perspectives of teachers on online teaching and assessments. Interactive Technology and Smart Education.

Joshi, A., Vinay, M., \& Bhaskar, P. (2020). NEP 2020: Silver lining for the Indian education sector. Available at: https://theeducationpost.in/nep2020-silver-lining-for-the-indian-education-sector/

Kizilcec, R. F., \& Halawa, S. (2015, March). Attrition and achievement gaps in online learning. In Proceedings of the Second (2015) ACM Conference on Learning@ Scale (pp. 57-66).

Kleiman, L. G. M., Wolf, M. A., \& Frye, D. (2014). Educating educators: Designing MOOCs for professional learning. In Massive Open Online Courses (pp. 127-156). Routledge. 
Bhaskar, P., Joshi, A. \& Dayalan P.

Koutsodimou, K., \& Jimoyiannis, A. (2015, November). MOOCS for teacher professional development: Investigating views and perceptions of the participants. In Proceedings of the 8th International Conference of Education, Research and Innovation-ICERI 2015 (pp. 6968-6977).

Malita, L., Tiru, L. G., \& Grosseck, G. (2018). MOOCs for Teachers Professional Development-A University Challenge. International Journal of Information and Education Technology, 8(3), 235-239.

Means, B., Toyama, Y., Murphy, R., Bakia, M., \& Jones, K. (2009). Evaluation of evidence-based practices in online learning: A meta-analysis and review of online learning studies.

Misra, P. (2018). MOOCs for teacher professional development: reflections and suggested actions. Open Praxis, 10(1), 67-77.

Mohapatra, S., \& Mohanty, R. (2017). Adopting MOOCs for afforable quality education. Education and information technologies, 22(5), 2027-2053.

Nagasampige, M., Subbaiah, G. D., \& Nagasampige, K. (2018). MOOCs in Indian University Education System: A Study on Awareness and Motivation among Students and Teachers of Indian Universities. Retrieved July, 2(9), 2.

Raza, S. A., Khan, K. A., \& Rafi, S. T. (2020). Online education \& MOOCs: Teacher self-disclosure in online education and a mediating role of social presence. South Asian Journal of Management, 14(1), 142-158.

Saadatmand, M., \& Kumpulainen, K. (2014). Participants' Perceptions of Learning and Networking in Connectivist MOOCs [Massive Open Online Courses]. Journal of Online Learning and Teaching.

Sanchez-Gordon, S., \& Luján-Mora, S. (2014). MOOCs gone wild. In Proceedings of the 8th International Technology, Education and Development Conference (INTED 2014) (pp. 1449-1458).

Sharma, S. (2020). MOOCS-an effective tool for professional development of teachers. Studies in Indian Place Names, 40(33), 137-138.

Smith, J. A. (1996). Beyond the divide between cognition and discourse: Using interpretative phenomenological analysis in health psychology. Psychology and health, 11(2), 261-271.

Smith, J., A., \& Osborn, M. (2003). Interpretative phenomenological analysis. Qualitative psychology: A practical guide to research methods, 53-80.

Tseng, T. H., Lin, S., Wang, Y. S., \& Liu, H. X. (2019). Investigating teachers' adoption of MOOCs: the perspective of UTAUT2. Interactive Learning Environments, 1-16.

Vinay, M., \& Bhaskar, P. (2020). Online Teaching amidst COVID-19 in India: An Outlook. Asian Journal of Distance Education, 15(2), 105-111.

Wang, Y., \& Baker, R. (2015). Content or platform: Why do students complete MOOCs. MERLOT Journal of Online Learning and Teaching, 11(1), 17-30.

Zheng, S., Rosson, M. B., Shih, P. C., \& Carroll, J. M. (2015, February). Understanding student motivation, behaviors and perceptions in MOOCs. In Proceedings of the 18th ACM conference on computer supported cooperative work \& social computing (pp. 1882-1895).

Zutshi, S., O'Hare, S., \& Rodafinos, A. (2013). Experiences in MOOCs: The perspective of students. American Journal of Distance Education, 27(4), 218-227. 